\title{
A Study of Students Data Base Followed up for Five Years in The New School of Medicine in Ndola, Zambia.
}

\author{
Duncan D Mugala \\ BSc(Human Biology), MB ChB, M Med (Surgery), FCS (ecsa) \\ Senior Lecturer Copper Belt University School of Medicine. \\ Honorary Lecturer University of Zambia School of Medicine. \\ Consultant Surgeon Ndola Teaching Hospital. \\ Senior Consultant General Surgeon. \\ Nchanga South Hospital, Chingola.(Retired)
}

\begin{abstract}
The School of Medicine on the Copper belt was started in October 2011 . We selected the best of the best students from CBU, the best of all students who did a two year study of A Levels in Zambia or abroad, the best Diploma holders of those who did a dental course done in Lusaka and indeed all who were degree holders of a science who had the best grades. Our students had to pass through the school of medicine for a period of five years in which they had tests, assignments and ends of terms and years examinations. After five years in the School of Medicine at the Ndola Teaching Hospital ; the first students graduated on $29^{\text {th }}$ September 2016. When our medical students joined the school of Medicine, they were exposed widely: Global health issues were encouraged as early as students entered medicine, some students published health publications worldly, they practiced medicine among the poor of Chipulukusu compound of Ndola and sometimes handled ethnic minorities in Ndola . In addition, some medical students travelled out of Zambia due to an international clinical rotation and often reported a greater ability to recognize disease presentations. The whole aim is that our field of teaching, the education and research Medicine at the Ndola Teaching Hospital, will become really wide, thus our desires are to expose out teacher experience[7].
\end{abstract}

Key words: Best, Education, Medicine, School , Students,

\section{INTRODUCTION}

These students started their medical training at the Ndola school of medicine based on the Copper belt School of medicine. They were the First CBU based Medical school after a lot of Political and national pressure to open the school of Medicine. The School of Medicine on the Copper belt was started in October 20 11.To get the students we selected the best of the best of the students from CBU, the best of all students who did a two year study of A Levels in Zambia or abroad, the Best Diploma holders of those who did a dental course done in Lusaka and indeed all who were degree holders of a science who had the best grades. When the students came they filled in a series of questions being the following:

Their names age and sex. We asked them to give us an area they came from.. We asked them to make a comment weather the course they were going to join met their aspirations or not and weather the Program Assessment was acceptable, easy or difficult.

We particularly asked them if they were in employment before they joined the school or not for a good reason: This thinking was based on what the other countries think of the students who enter medicine are supposed to be. It is believed that students entering the healthcare field 
perform well if they have had an early exposure to careers or are professionals that work and collaborate to treat patients ; the end result is vital to a well-rounded education. As such, it is believed that a student involvement in hospital-organized programs is encouraged for anyone interested in medicine[1].

Our students had to pass through the school of medicine for a period of five years in which they had tests, assignments and ends of terms and years examinations. After five years in the School of Medicine at the Ndola Teaching Hospital ; the first students graduated on $29^{\text {th }}$ September 2016.

When our medical students joined the school of Medicine, they were exposed widely: Global health issues were encouraged as early as students entered medicine, some students published health publications worldly, they practiced medicine among the poor of Chipulukusu compound of Ndola and sometimes handled ethnic minorities in Ndola. In addition, some medical students travelled out of Zambia due to an international clinical rotation and often reported a greater ability to recognize disease presentations,

The students went through a more comprehensive physical ward round examination skills, with less reliance on expensive imaging equipment which the hospital did not have compared to many European schools. Our aim was a call for more training and opportunities[4].

We planned to publish the education experience of our students. The aim of this publication is based on announcing the Teacher Education articles focusing on the practice, research and policy of teacher education[6].We also expect this paper will prompt internal and external criticism, demands for accountability, and an authentic desire to better understand processes associated with learning to teach.

The whole aim is that our field of teaching, the education and research Medicine at the Ndola Teaching Hospital, will become really wide, thus our desires are to expose out teacher experience[7].

\section{PATIENTS AND METHODS}

We selected the Best of the best applicants from CBU students, The Best of the A levels students, the best Degree holders in science and the best Diploma holders of the course of Dentistry that occurs in Lusaka Zambia.

We Kept a record of the results of tests they went through, the assignments they wrote and were assessed, the written examinations and Viva examinations they went though. After all these activities the students were presented to the Board Examinations School of medicine meeting. The occurred at the end of every year; a Diagnosis was made whether they passed or not . Those who passed the year proceeded to go on for the following year. Some had to repeat the year, some were asked to leave the school of medicine if they poorly failed.

During the Clinical examinations the students underwent the now standard of objective structured clinical examinations (OSCEs) in assessing medical students. However, for five years, we never did allow clinical teachers to undergo what is known as the Objective-structured teaching encounters (OSTEs). 


\section{The Number of students and age distribution}

\section{RESULTS}

They were 70 students who started education at the new Medical school.

There were 40 males and 30 females (M:F 1.3:1).

There were two programs which started; these were MB ChB and BDS. In MB ChB there were 43 students comprising of 14 Female students and 29 males. The BDS program complied of 16 females and 11 male a total of 27 students.

The youngest student was 19 years old and the oldest was 45 years old.

Table I. Students Age range

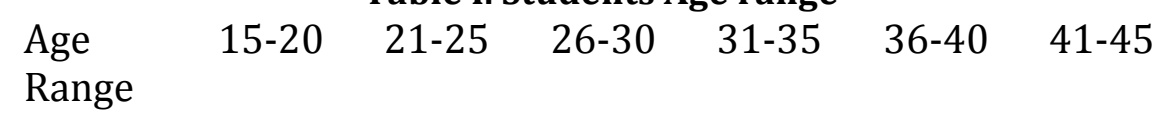

No. of

$\begin{array}{lllllll}\text { Students } & 04 & 33 & 18 & 07 & 07 & 01\end{array}$

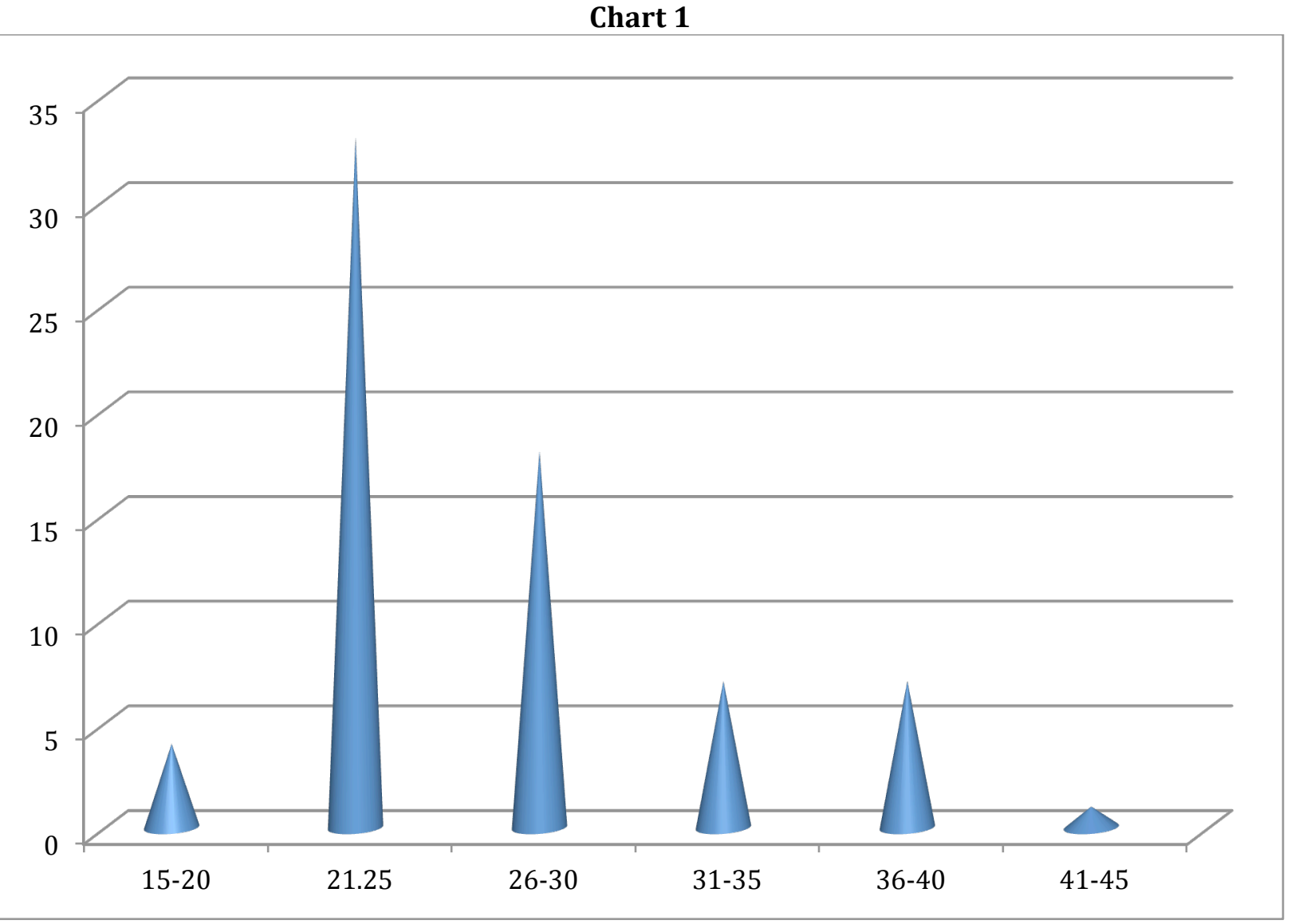

Table II. Students Age range VS Male or Female

$\begin{array}{lllllll}\text { Age } & 15- & 21-25 & 26-30 & 31-35 & 36-40 & 41- \\ \text { Range } & 20 & & & & & 45 \\ \text { Males } & 01 & 20 & 10 & 04 & 05 & 01 \\ \text { Females } & 03 & 13 & 08 & 03 & 02 & 0.0 \\ \text { Total } & 04 & 33 & 18 & 07 & 07 & 01\end{array}$

Our largest number of students were aged between 21 and 25 year old students. The most frequent ages were 23 and 24years of age. The mode age was 23.5 years. 


\section{Chart 2}

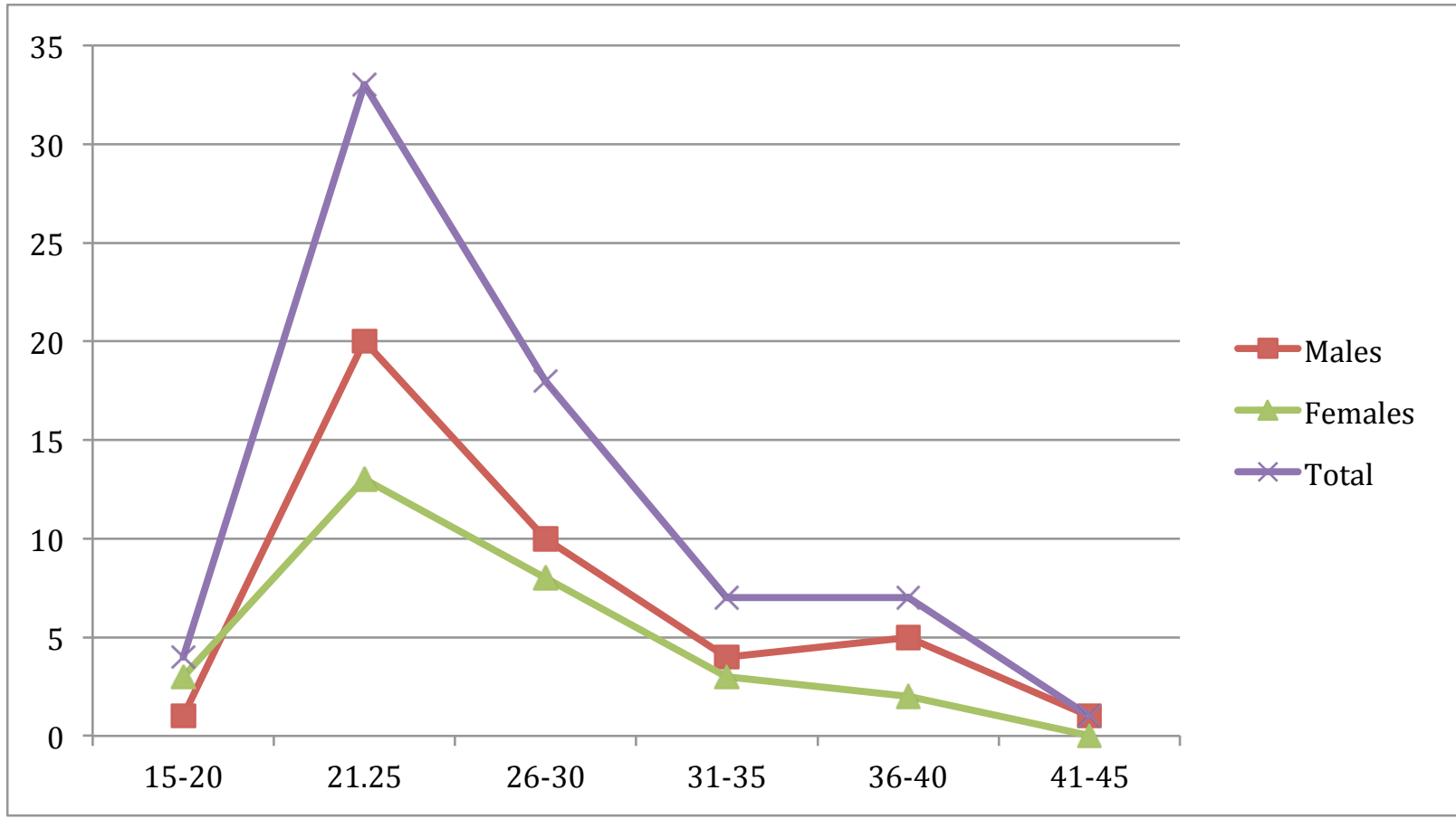

The Students who joined the School of Medicine came from all parts of Zambia. The most popular areas were the Copper belt and Lusaka

Table III. Where the students came from

Town Of Copper Chipat Southern Central Luapula Northern North/west Lusaka Residence Belt a

Number of

Students

27

$02 \quad 04$

02

04

01

02

Chart 3

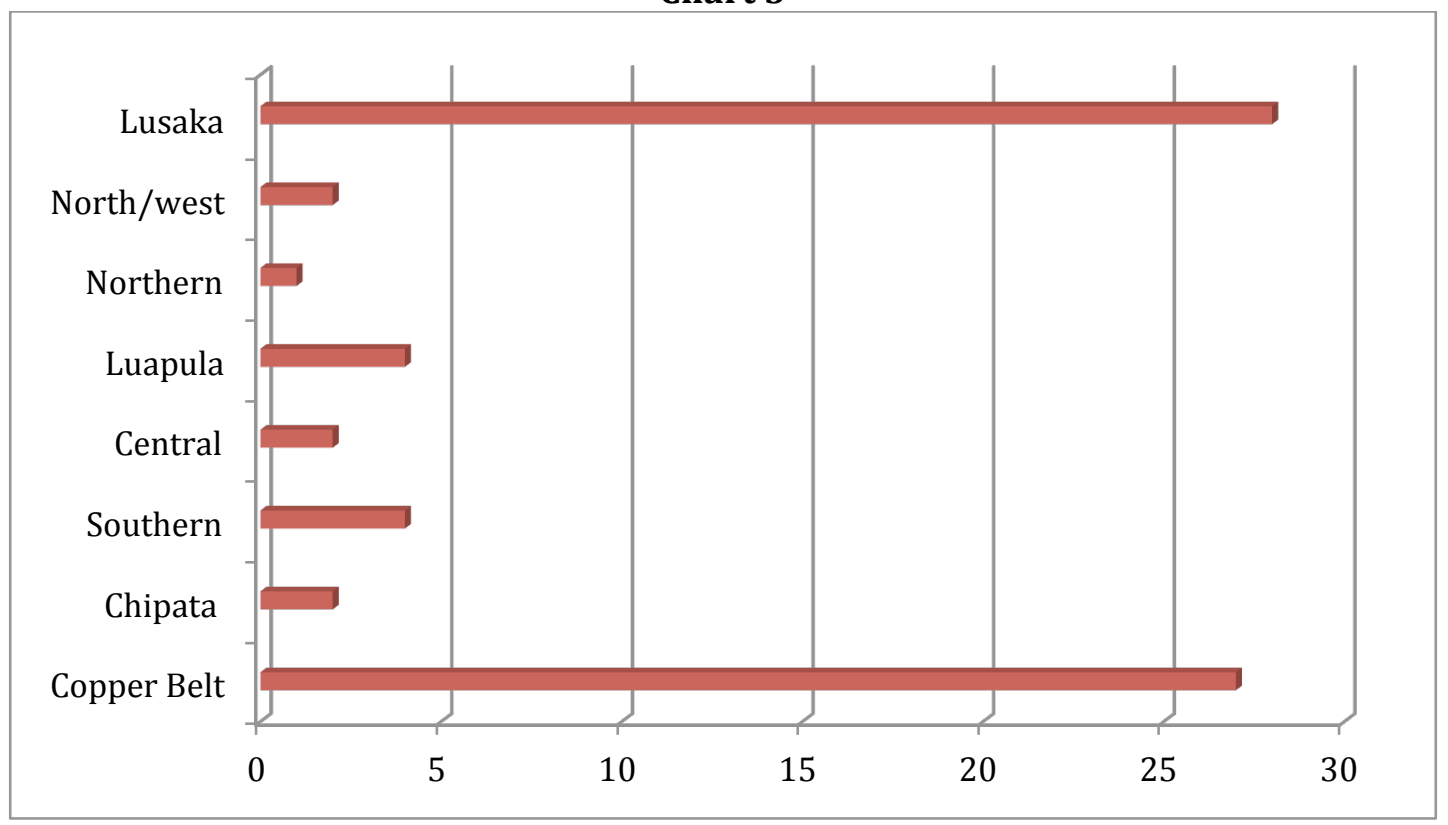




\section{The Qualifications of the Students}

The students who were admitted to the school of medicine had to pass thought the acceptable qualifications.

The students who came from the CBU had to have spent at least two years at the CBU in the science departments. Some students had done a two year A Level science and English course. The A Level of qualification were set up and had to be acceptable. Some applicants were students from other Universities and had a BSc degree in Science to be accepted into the school of medicine.

There were also a very special level of students who had gone through the Dental School based in Lusaka and had worked under the Government Dental system for at least two years and then were allowed to apply for BDS. This was also a new event in that this was to be the first BDS course in Zambia. These applicants had to have high level Diplomas and were of high level practice of Dentistry to be accepted.

The Following were the acceptable qualifications of students.

Table IV. Status of student at start of Education

\begin{tabular}{|c|c|c|c|c|c|}
\hline Oualifications & Full A & BSc & Diploma & Two vear & Totals \\
\hline the & -Levels & Science & In & course & applicants \\
\hline Applicant & & & Dentistry & more at CBU & \\
\hline Number & & & & & \\
\hline Applicants(\%) & $05(7.2)$ & $25(35.7)$ & $24(34.3)$ & $16(22.9)$ & $70(100)$ \\
\hline Years & & & & & \\
\hline Worked(\%) & 0 & $10(40)$ & $21(87.5)$ & 0 & $31(44.3)$ \\
\hline
\end{tabular}

Chart 4

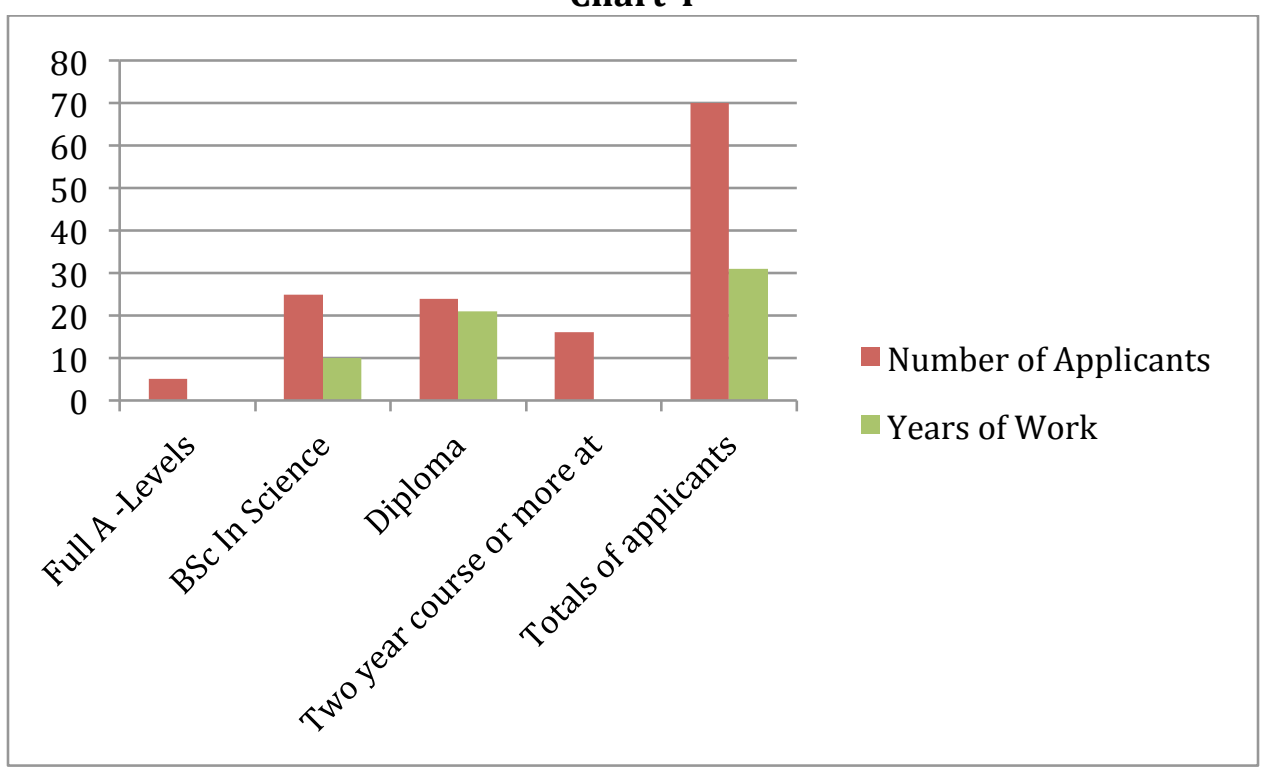

\section{The Questions the students responded}

The applicants were asked Several questions. These were:

1. On whether the course they were going to join met their aspirations or not; all the students said that the new Medicine school met their aspirations. 
2. On whether the Program Assessment was acceptable, easy or difficult. Three students said it was difficult. One student said it was easy and the rest said it was acceptable.

3. We also asked them if they were in employment before they joined the school or not. We saw that $31(44.3 \%)$ were in employment before they started education( Table IV).

\section{The End of year One results}

By the end of the first year in the new Medical School two female students and one man stopped the education and only 67 remained in the School.

Among the students the following were the result of their end of year examination appearance.

Table V. End of year 1 examination results

\begin{tabular}{|l|c|l|r|}
\hline GRADE & NUMBER & GRADE & $\%$ \\
\hline $\mathrm{A}$ & 16 & $\mathrm{~A}$ & 23.9 \\
\hline $\mathrm{B}+$ & 16 & $\mathrm{~B}+$ & 23.9 \\
\hline $\mathrm{B}$ & 16 & $\mathrm{~B}$ & 23.9 \\
\hline $\mathrm{C}+$ & 18 & $\mathrm{C}+$ & 26.9 \\
\hline $\mathrm{C}$ & 0 & $\mathrm{C}$ & 0 \\
\hline $\mathrm{D}$ & 0 & $\mathrm{D}$ & 0 \\
\hline $\mathrm{E}$ & 1 & $\mathrm{E}$ & 1.5 \\
\hline & & & \\
TOTAL & 67 & & 100 \\
\hline
\end{tabular}

Table VI. End of year 1 examination results

\begin{tabular}{|l|r|}
\hline Mark & Percentage(\%) \\
\hline Highest & 83 \\
\hline Lowest & 39 \\
\hline Average & 68.50 \\
\hline
\end{tabular}

Chart 5

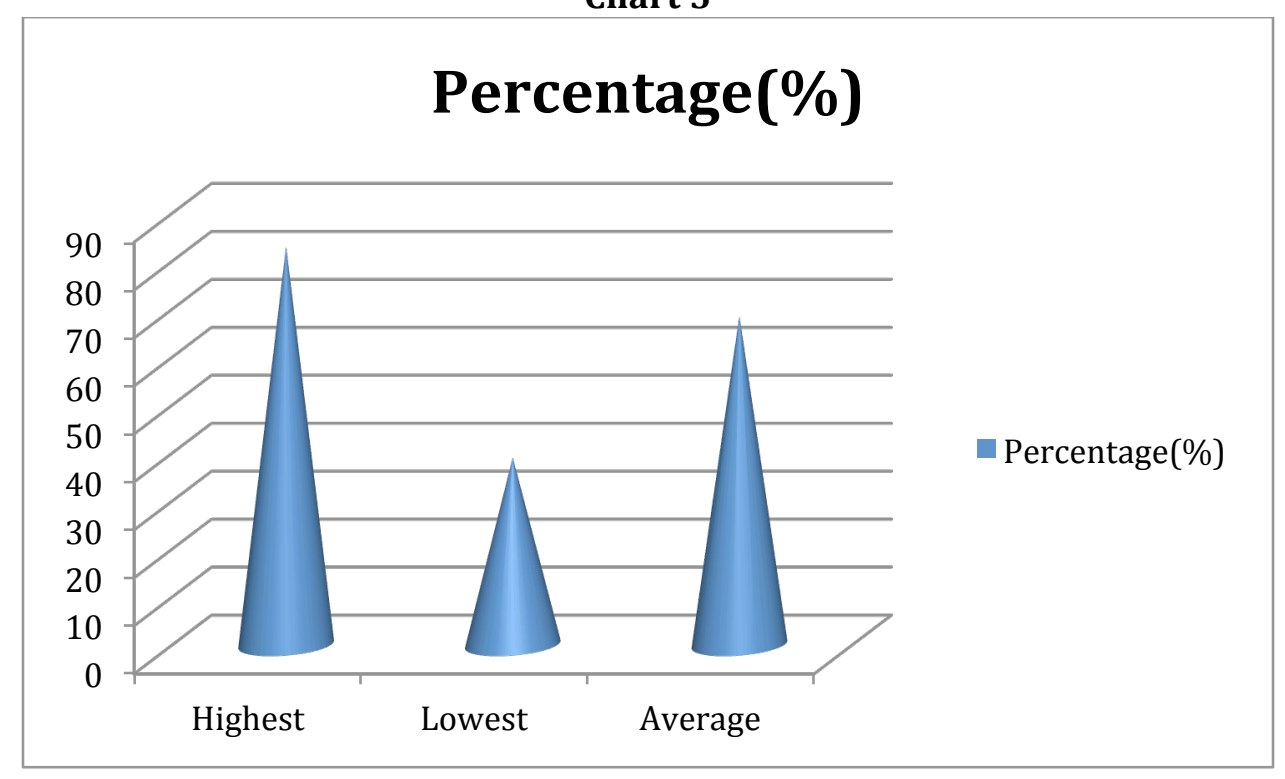


TableVII. The age of the students compared with the Examination results

$\begin{array}{lllllll}\text { Age } & 15-20 & 21.25 & 26-30 & 31-35 & 36-40 & 41-45 \\ \begin{array}{l}\text { Range } \\ \text { Number of }\end{array} & 04 & 32 & 18 & 07 & 07 & 01 \\ \begin{array}{l}\text { students } \\ \text { A }\end{array} & 01(25) & 04(12.5) & 04(22.2) & 0 & 02(28.6) & 0 \\ \text { B } & 03(75) & 18(56.3) & 09(50) & 05(75.4) & 02(28.6) & 0 \\ \text { C } & 0 & 08(25) & 05(27.8) & 02(28.6) & 03(42.9) & 0 \\ \text { E } & 0 & 0 & 0 & 0 & & 01(100)\end{array}$

TableVIII. The Qualification of the students compared with the Examination results

$\begin{array}{lllll}\begin{array}{l}\text { Educational } \\ \text { Qualification }\end{array} & \begin{array}{l}\text { A- } \\ \text { Levels }\end{array} & \begin{array}{l}\text { BSc in } \\ \text { Qualification }\end{array} & \begin{array}{l}\text { Diploma } \\ \text { Qualification }\end{array} & \begin{array}{l}2 \text { Years } \\ \text { CBU } \\ \text { Science }\end{array} \\ \begin{array}{l}\text { Number of } \\ \text { students }\end{array} & 05 & 25 & 23 & 16 \\ \text { A } & 02(40) & 06(24) & 03(13.0) & 03(18.8) \\ \text { B } & 02(40) & 13(52) & 13(56.5) & 10(62.5) \\ \text { C } & 01(20) & 06(24) & 07(30.3) & 03(18.8) \\ \text { E } & 0 & 0 & 01(4.3) & 0\end{array}$

\section{The final course ended after five}

The final course ended after five years in the School of medicine. Of the 70 students who joined the medical school, the following took place.

One student left the CBU school of medicine and moved on to another university and continued the education.

Three students retired from the university for a series of reasons; there were two women and one man.

Nine students were still part of the school of medicine but were no able to graduate for various failures during the course of education and it is hoped they will graduate one day.

Finally there were $20 \mathrm{BDS}$ and $36 \mathrm{MBCh}$ students who graduated; a total of $56(80 \%)$ first five year CBU Ndola Teaching Hospital based students.

The following were their grades at graduation: At the end of year 5 at medical school the following were the results in general surgery in $\mathrm{MBChB}$.

Table IX. End of year 5 examination results: $M B C h B$

$\begin{array}{llll}\text { GRADE } & \text { NUMBER } & \text { GRADE } & \text { PERCENTAGE } \\ \text { A } & 10 & \text { A } & 27.8 \\ \text { B } & 15 & \text { B } & 41.6 \\ \text { C } & 07 & \text { C } & 19.4 \\ \text { D } & 03 & \text { D } & 8.3 \\ \text { E } & 01 & \text { E } & 2.8 \\ \text { TOTAL } & 36 & & 100\end{array}$




\section{Chart 6}

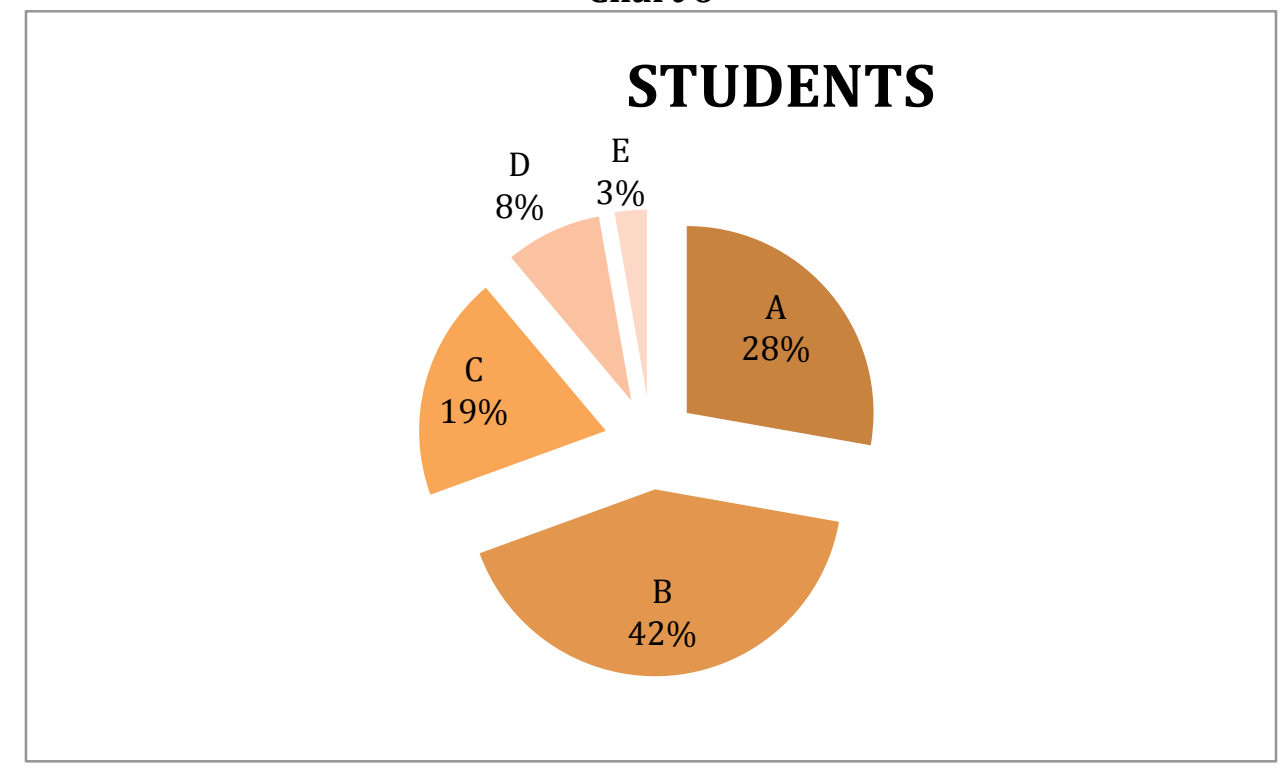

Table X. End of year 5 examination results MB ChB

Highest Mark Lowest Mark Average
End of year1(\%)

83

39

68.5
End of Year 5(\%)

90

37.7

68.5

Chart 7

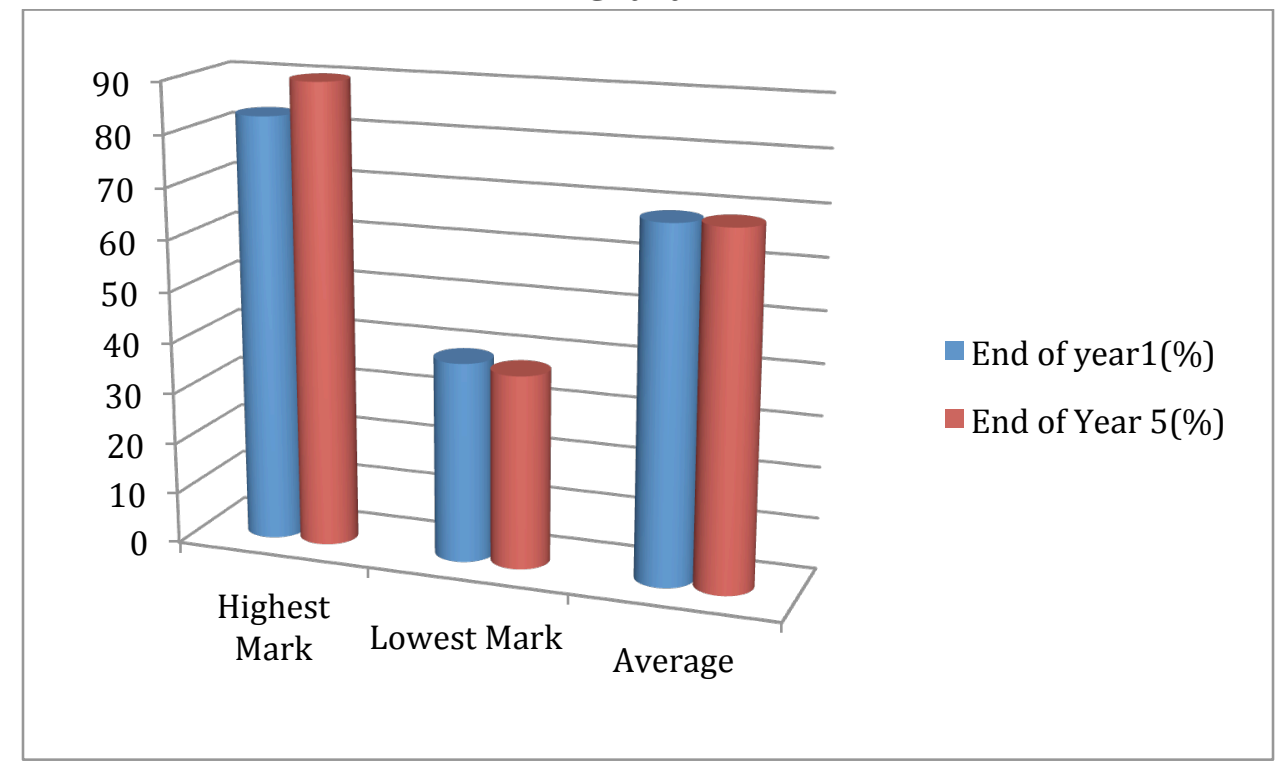




\begin{tabular}{llll} 
& \multicolumn{4}{c}{ Table XI. End of year $\mathbf{5}$ examination results, BDS } \\
GRADE & NUMBER & GRADE & PERCENTAGE \\
A & 8 & A & 33.4 \\
B & 11 & B & 45.8 \\
C & 5 & C & 20.8 \\
D & 0 & D & 0 \\
E & 0 & E & 0 \\
TOTAL & 24 & & 100
\end{tabular}

Chart 8

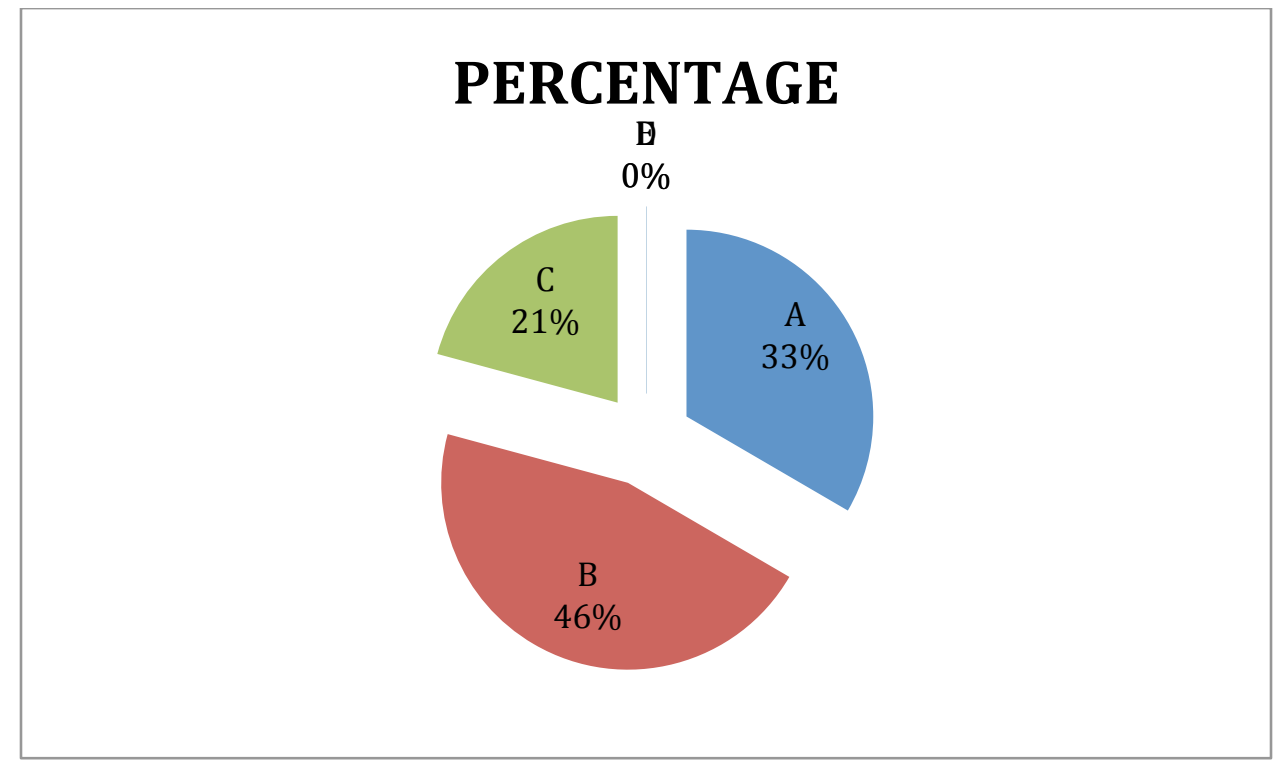

Of the 24 BDS student four students could not graduate. They were failed in the various courses they went through and on the Final results they were made to repeat the course of medicine.

So the final of the BDS students, only $20(74.1 \%)$ out of 27 graduated.

Table XII. End of year 5 examination results BDS

End of Year 5

Highest

Mark

86

Lowest

50

Mark

Average

67.5 


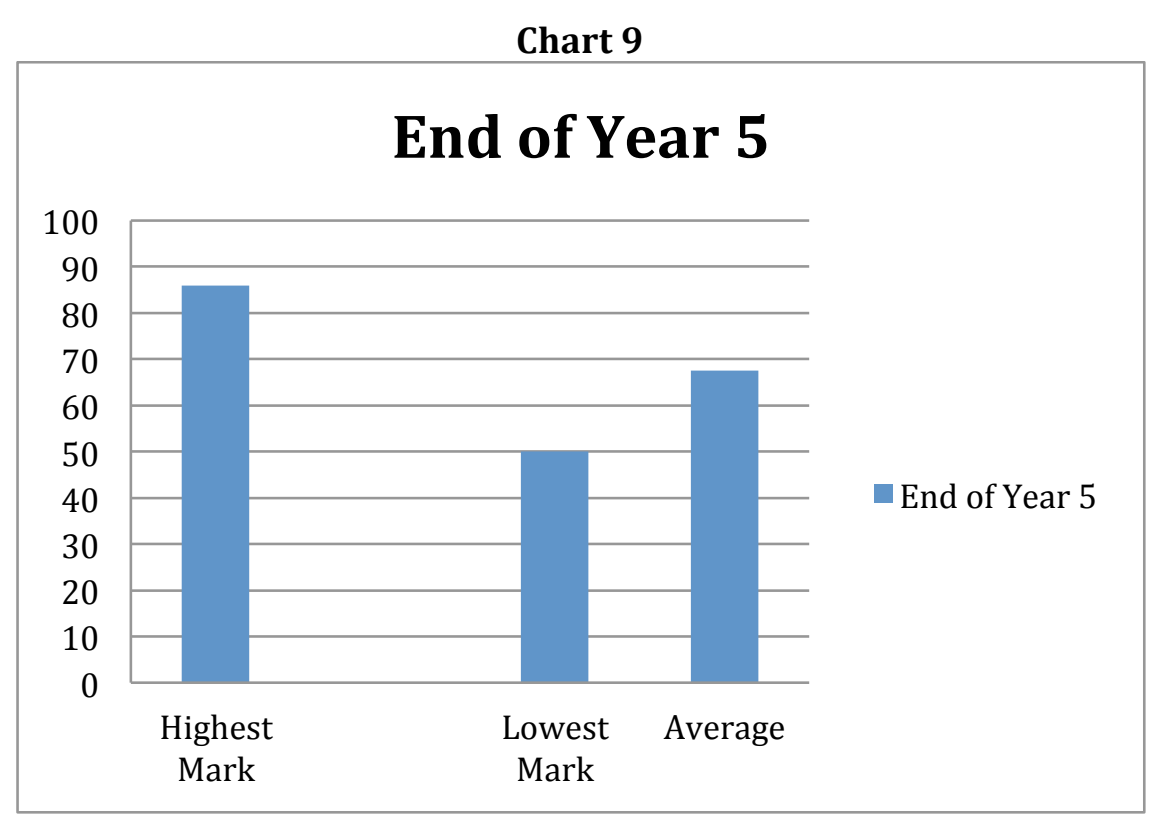

\section{The Feeling of the students at the end of the year}

The Feeling of the students as they were coming to the end of the course were sought out, a sample of their feeling were asked for. It was asked only concerning those who were in MB ChB. Those in DBS were not questioned.

Only ten students were asked personally and they gave their response as follows:

\section{Table XIII. Feeling of the student at end of course}
Number of Students
Response
02
They were happy the end has come to the end and they really wanted to leave.
02
They were fed up, the course had taken too long.
06
They were tired and could not stay any longer.

The remaining 27 were never asked.

\section{The training of clinical lecturers during the year}

Some medical schools allow their teachers to undergo what is known as Objective-structured teaching encounters (OSTEs). This is particularly done for Clinical teachers. For this Medical school, the issue was not done.

\section{DISCUSSION AND CONCLUSION}

Seventy students were admitted to the new School of Medicine at the Ndola Teaching hospital on the Copper belt in Zambia. They comprised of 40 males and 30 females (M:F 1.3:1). By and large this was an almost acceptable level in that the females were almost equal to the men.

There were two programs which started; these were MB ChB and BDS. The big issue was the starting of the BDS. In Zambia all BDS students were trained abroad. In the country we only offered a Dental college in Lusaka. So this was the first starting of the Dentist Medical degree being offered. It was a challenge and a trial but it went through. 
The majority of our students were between 21years to 25years of age. The youngest student was 19 years old and the oldest was 45 years old. We believe this was an acceptable ageing range.

After one year of studying the results were looked at concerning the students age and the students qualifications they had acquired when they applied. Looking at the age; it showed that those who were older had a large number of students who had C pass(42.9\%). It stands out that it was significant. Looking at the students Qualification there were several significant issues:

Among A levels students $40 \%$ had As and $40 \%$ had Bs, only $20 \%$ had Cs, whereas those student from CBU had only $18 \%$ of their students had As followed by $62 \%$ student who had Bs This is a significant observation. Among the Diploma students, they had only $13 \%$ had As but had 30\% Cs and 4\% who actually failed. These seem to be issue we should keep an eye on.

It is generally believed that those who seek medicine are said to be, evidently, those with increased high school and undergraduate student participation in hospital-based volunteer programs or affairs. This tends to produce a bright set of future physicians, physician's assistants, and nurses with promising intellectual and interpersonal qualities [1]. In our students a high number never had such an experience, but a good number were involved in medical practice, for example, the Dentist trainers and the holders of BSc degrees holders. Perhaps this has reduced our failure rate in our students.

One of the features we feared was the known fact that students would burn out. It is known and described by many researchers as levels of burnout and impostor syndrome (IS) in medical students does occur[2], We unfortunately never carried this burnout and IS. But we suspect the students who actually dropped out of the team of student may have been due to these IS or Burn out in students. By the end of the first year in the new Medical School two female students and one man stopped the education and only 67 remained in the School. We believe that the psychological effect of IS and burnout cannot be ignored. We need to study this in some students, particularly those in $4^{\text {th }}$ and $5^{\text {th }}$ year students. Jennifer etal believe that IS exists in a significant percentage of medical students and appears to peak in the fourth year of medical school. In addition they believe that it is associated with multiple burnout indices and, likely, psychological distress. Of the MB ChB students we asked ten of them how they felt as they were in Fifth year. Six were tired and could not stay any longer, two were fed up, the course had taken too long and two were happy the end has come to the end and they really wanted to leave. We wish we had asked all the students. The Burn out effect were real.

There was also another occurrence that needed attention. This concerned us that we had not researched after five years of our the relations between us and the students, it is called a social justice and teacher education relationship: This is a systematic review of empirical relation work carried on our students and our justice in the field are followed. This thing is very important and the hope is that it will be carried out in the years to come. In America this work has been done - Mills etal[5].

Our students have qualified and are going out there in all parts of Zambia and we will forget about them. It is our hope that our students who have qualified should be part of our dream. We should create the journal club that should be more formally incorporated into the medical educational curriculum. This will keep them in touch with us. It was Sir William Osler who 
organized a journal club at McGill University in1875 and it worked [3].It is hoped ours will also work out.

Our school of medicine went on for Five years and 57 students qualified well. 13 students were dropped out or were left behind. Thus it is not usual to have $100 \%$ pass. It is worse with other courses. Edwards etal have quoted that

'the academic success rate of developmental mathematics students at community colleges is alarmingly low'.

It is Known that in America more than $60 \%$ of the nation's 14 million community college are required to take at least one developmental mathematics class before they are eligible to enrol in college credit courses.

$80 \%$ of the students who get a place in developmental mathematics.

Do not successfully complete any college.

level mathematics course within 3 years (Bailey, Jeong, \&Cho, 2010).

Many students spend long periods of time repeating courses and ultimately leave college without a credential. This means that millions of students fail to acquire essential mathematics skills and are unable to progress toward their career and life goals[8].

This is typical of America. We do not know what happens at CBU, the Mathematics is used for various courses, It may be similar. As for the School of Medicine we had taken in the Best of the Best ( the cre'me de la cre'me) to enter the first school in Ndola. There were MBChB and BDS chosen applicants. Among the MBChB there were 43 students comprising of 14 Female students and 29 males. The BDS program complied of 16 females and 11 male a total of 27 students. Naturally we expected an almost $100 \%$ passage but not so; the end after five years in Medical school there were $36 \mathrm{MB}$ ChB and only 20 BDS student i.e. 81.4\% went through and $18.6 \%$ of our students did not make it. Ours passing percentage, fortunately, is not alarmingly low. It is acceptable and good since we had started with the cre`me de la cre`me.

We in Ndola have just finished our five years of running a Medical school, we have publish papers on various sciences of Medicine but unfortunately very little on Teacher Education.

Others like Knight et al have completed a 5 years study as editors of Journal of Teacher Education (JTE),they have published four full volumes[9] .

We need to rethink our approach and always consider our status of seeking to improve our teaching, educating and researching regarding our teaching job.

We spent five years teaching these students. Our biggest problem was lack of more lecturers who were needed to come and teach our students. The numbers we had, had to do a lot of extra work to cope up with the needed teaching. Other centers have quite the opposite; for example Ingersoll, Merrill, and Stuckey, 2014 report that Teacher turnover rates are most rapid for beginners. The say that about $41 \%$ of teachers leave in their first five years on the job and the turnover rate is considerably higher in poor schools than it is in more affluent ones[10]. Hannan, et all suggest several ways to save the teachers. They suggest that establishing highquality and reliable new teacher support systems involves many different, namely; interlocking organizational processes, setting up roles for them and their functions, teacher time allocation and scheduling, evaluation processes, professional development, and human resources 
development[10]. Although we have not lost workers. We have not deliberately done a lot of deliberates to prevent the loss of our Teachers. We have taken it that teachers will always be available.

Some medical schools allow their teachers to undergo what is known as Objective-structured teaching encounters (OSTEs). These are used across many disciplines to assess the lecturers teaching ability. We never had it throughout our five years. During this course ; the Standardized patients (SPs)- our patients and standardized learners (SLs)- our students, would have been used and trained/ instructed to participate in a standardized encounter with specific acts of picking up the following from us the teachers; cognitive, social, and behavioral errors, including professionalism lapses in us and help us to be corrected and this would make us better lectures[11].

During the Clinical examinations the students underwent the now standard of objective structured clinical examinations (OSCEs) in assessing medical students. Not every lecturer accepted this OSCE .But it was the School of medicine standard demand. It is felt that a potential familiarization training for the examiners would have caused all the clinical teachers would have fully accepted it[12].

\section{Referances}

Brandon Muncan, Nomrota Majumder and Nicolae Tudose From high school to hospital: how early exposure to healthcare affects adolescent career ideas Int J Med Educ. 2016; 7:370-371; doi: 10.5116/ijme.5801.f2cc | Published 06/11/2016

Jennifer A. Villwock ${ }^{1}$, Lindsay B. Sobin ${ }^{2}$, Lindsey A. Koester ${ }^{3}$ and Tucker M. Harris ${ }^{4}$ Impostor syndrome and burnout among American medical students: a pilot study

Int J Med Educ. 2016; 7:370-371; doi: 10.5116/ijme.5801.f2cc | Published 06/11/2016

M. Linzer. The journal club and medical education: over one hundred years of unrecorded history. 3Postgrad Med J 1987;63:475-478 doi:10.1136/pgmj.63.740.475

Drain, Paul K. Primack, Aron, ; Hunt, D Dan , Fawzi, Wafaie W. Holmes, King K. Gardner, Pierce .Global Health in Medical Education: A Call for More Training and Opportunities ;Academic March 2007 - Volume 82 - Issue 3 - pp 226-230 doi: 10.1097/ACM.0b013e3180305cf9

Mills, Carmen, Ballantyne, Julie. Social Justice and Teacher Education: A Systematic Review of Empirical Work in the Field. Journal of Teacher Education, Vol. 67, No. 4, September-October

Daniel P. Liston, Jennifer Whitcomb and Hilda Borko. Prpeer-Reviewed Periodical, Journal of Teacher Education,Vol. 67, No. 4, September-October

Tatto, Maria Teresa; Richmond, Gail; Andrews, Dorinda J. Carter, The Research We Need in Teacher Education. Journal of Teacher Education Articles from Vol. 67, No. 4, September-October

Edwards, Ann R., Sandoval, Carlos, McNamara, Haley Designing for Improvement in Professional Development for Community College Developmental Mathematics Faculty Journal of Teacher EducationKnight, Stephanie L, Lloyd, Gwendolyn M, Arbaugh, Fran, Garrison, David A, McDonald, Scott P., Nolan, James Jr, Whitney, Anne Elrod. FiveYear Retrospective; Journal of Teacher Education Articles from Vol. 66, No. 5, November-December 2014-2015 Reviewer Appreciation

Hannan, Maggie,Russell, Jennifer Lin; Takahashi, Sola; Park, Sandra. Using Improvement Science to Better Support Beginning Teachers: The Case of the Building a Teaching Effectiveness Network; Articles from Vol. 66, No. 5, November-December 2014-2015.

Constance R. Tucker, Beth A. Choby, Andrew Moore, Robert Scott Parker, Benjamin R. Zambetti, Sarah Naids, Jillian Scott, Jennifer Loome, Sierra Gaffney. Speaking up: Using OSTES to understand how medical students address professionalism lapses, Med Educ Online 2016, 21: 32610.

Katharine Reid, David Smallwood, Margo Collins, Ruth Sutherland,Agnes Dodds.Taking osce examiner training on the road: reaching the masses. Med Educ Online 2016, 21: 323 